\title{
Perhitungan Modal Kerja dan Volume Usaha Koperasi Politeknik Balikpapan
}

\author{
Ramli $^{1^{*}}$, Nur Vita Opu ${ }^{2}$ \\ ${ }^{1,2}$ Politeknik Negeri Balikpapan \\ ramli@poltekba.ac.id
}

\begin{abstract}
In times of economic and monetary crisis, cooperatives have contributed to the national economy, while large and medium enterprises in crisis, small businesses and cooperatives can survive even the most cooperative can develop business in other sectors. In accordance with the objectives to be achieved as mentioned above, in order to increase the ability of cooperatives as a cornerstone of the national economy strong capital required to support the growth of cooperatives better, not least cooperative polytechnic. The purpose of this study was to determine the effect of working capital to the volume of business on a cooperative polytechnic. This research method is quantitative descriptive. Data collected with good documentation techniques at variable working capital and business volume. The result shows that the effect on the working capital of the business volume with an increase in working capital amounted to 16:20\% followed by an increase in business volume amounted to $16.59 \%$.
\end{abstract}

Keywords : Working capital, cooperative enterprises and business volume

\begin{abstract}
Abstrak
Dalam masa krisis ekonomi dan moneter, koperasi telah memberikan kontribusi kepada perekonomian nasional, ketika perusahaan besar dan menengah mengalami krisis, usaha kecil dan koperasi mampu bertahan bahkan sebagian besar koperasi dapat mengembangkan usaha pada sektor-sektor lain. Sesuai dengan tujuan yang ingin dicapai seperti tersebut diatas, maka dalam usaha meningkatkan kemampuan koperasi sebagai soko guru dalam perekonomian nasional diperlukan modal yang kuat untuk menunjang tumbuhnya koperasi secara lebih baik, tak terkecuali koperasi politeknik. Tujuan penelitian ini adalah untuk mengetahui pengaruh modal kerja terhadap volume usaha pada koperasi politeknik. Metode penelitian ini adalah deskriptif kuantitatif. Data dikumpulkan dengan teknik dokumentasi baik pada variabel modal kerja maupun volume usaha. Hasilnya menunjukkan bahwa modal kerja berpengaruh terhadap volume usaha dengan adanya peningkatan pada modal kerja sebesar $16.20 \%$ diikuti peningkatan volume usaha sebesar $16,59 \%$.
\end{abstract}

Kata kunci: Modal kerja, Koperasi dan volume usaha

\section{Pendahuluan}

Dalam masa krisis ekonomi dan moneter, koperasi telah memberikan kontribusi kepada perekonomian nasional, ketika perusahaan besar dan menengah mengalami krisis, usaha kecil dan koperasi mampu bertahan bahkan sebagian besar koperasi dapat mengembangkan usaha pada sektor-sektor lain.
Trilogi pembangunan akan terwujud apabila peranan dan tanggung jawab masyarakat khususnya masyarakat pendidikan telah tumbuh dan meningkat sehingga mereka mampu mengurus dirinya sendiri dan berpartisipasi secara nyata dalam pembangunan atas dasar kekeluargaan dan sukarela sehingga dapat menikmati hasilhasil dari usaha koperasi. 
Untuk tujuan tersebut dalam pelaksanaan pembangunan ekonomi berbagai sektor, koperasi diberi peranan dan ruang gerak yang luas. Dalam hal ini langkah yang ditempuh untuk memantapkan kemampuan koperasi pegawai khususnya pada Institusi Pemerintah dan koperasi primer lainnya. Sesuai dengan Garis-garis Besar Haluan Negara, koperasi akan dijadikan sebagai salah satu wadah untuk meningkatkan kesejahteraan anggota khususnya dan masyarakat pada umumnya.

Sebagai salah seorang pengurus inti di koperasi Politeknik Balikpapan, sudah barang tentu mengetahui dengan jelas, perkembangan Koperasi, sejak berdirinya tahun 2008 sampai sekarang.

Bertitik tolak dari uraian tersebut penulis ingin meneliti apakah benar bahwa modal kerja berpengaruh terhadap peningkatan volume usaha koperasi.

\section{Metodologi}

Menurut Panji Anoraga dan Ninik Widiyanti (dalam Panji Anoraga dan Ninik Widiyanti,1992;3 ) menyebutkan pengertian Koperasi sebagai berikut :

"Koperasi berasal dari perkataan Co dan Operation, yang mengandung arti bekerja sama untuk mencapai tujuan. Oleh karena itu Koperasi adalah suatu perkumpulan yang beranggotakan orang-orang atau badanbadan yang memberikan kebebasan masuk dan keluar sebagai anggota dengan bekerjasama secara kekeluargaan

Tabel 2. Neraca Koperasi Politeknik Negeri Balikpapan Per 31 Desember 2015 menjalankan usaha, untuk mempertinggi kesejahteraan jasmaniah para anggotanya.

Untuk memperoleh data yang diperlukan penulis menggunakan teknik pengumpulan data diantaranya ;

1. Pengumpulan data primer

Dalam pengumpulan data primer penulis langsung terjun dilapangan yaitu dengan menggunakan :

a. Teknik Observasi,

b. Teknik Interview

c. Teknik dokumentasi

2. Pengumpulan Data Skunder

Dalam memperoleh data dengan cara skunder ini adalah dengan mengadakan penelitian perpustakaan, yaitu penulis secara langsung menghimpun data-data melalui penerbitan, dalam bentuk buku-buku, laporan tahunan atau brosur-brosur yang ada hubungannya dengan masalah yang akan diteliti.

\section{Hasil dan Diskusi}

Dari serangkaian pengambilan data dan setelah diolah melalui mekanisme pelaporan standar keuangan koperasi, berikut didapatkan paparan kinerja Koperasi Politeknik Negeri Balikpapan. 


\begin{tabular}{|c|c|c|c|c|c|}
\hline \multicolumn{4}{|c|}{ I. Aktiva Lancar } & \multicolumn{2}{|c|}{ III. Passiva Lancar } \\
\hline 1. & Kas & 19.954 .448 & 6. & $\begin{array}{l}\text { Hutang } \\
\text { Usaha }\end{array}$ & 311.500 \\
\hline 2. & Bank & 12.095 .700 & 7. & Hutang Pajak & 3.213 .285 \\
\hline 3. & $\begin{array}{l}\text { Piutang } \\
\text { Usaha }\end{array}$ & 89.227 .864 & 8. & $\begin{array}{l}\text { Simpanan } \\
\text { Pokok }\end{array}$ & 7.600 .000 \\
\hline & Jumlah & 121.278 .012 & 9. & $\begin{array}{l}\text { Simpanan } \\
\text { Wajib }\end{array}$ & 94.230 .000 \\
\hline \multicolumn{3}{|c|}{ II. Aktiva Tetap } & & Jumlah & 105.354 .785 \\
\hline 4. & Inv.Kantor & 28.675 .000 & $\begin{array}{l}\mathrm{I} \\
\mathrm{V}\end{array}$ & Ekuitas & \\
\hline \multirow[t]{3}{*}{5.} & $\begin{array}{l}\text { Akumulasi } \\
\text { Peny. }\end{array}$ & $(8.684 .790)$ & $\begin{array}{l}1 \\
0\end{array}$ & $\begin{array}{l}\text { Laba Usaha } \\
\text { ditahan }\end{array}$ & 27.875 .110 \\
\hline & Jumlah & 19.990 .210 & $\begin{array}{l}1 \\
1\end{array}$ & $\begin{array}{l}\text { Laba Usaha } \\
\text { Berjalan }\end{array}$ & 8.038 .327 \\
\hline & $\begin{array}{l}\text { TOTAl } \\
\text { AKTIVA }\end{array}$ & 141.268 .222 & & & 141.268 .222 \\
\hline
\end{tabular}

Tabel 3. Neraca Politeknik Negeri Balikpapan Per 31 Desember 2014

\begin{tabular}{|c|c|c|c|c|c|}
\hline \multicolumn{3}{|c|}{ I. Aktiva Lancar } & \multicolumn{3}{|c|}{ III. Passiva Lancar } \\
\hline 1. & Kas & 27.679 .680 & 6. & $\begin{array}{l}\text { Hutang } \\
\text { Usaha }\end{array}$ & 0 \\
\hline 2. & Bank & 29.034 .651 & 7. & Hutang Pajak & 2.320 .138 \\
\hline 3. & $\begin{array}{l}\text { Piutang } \\
\text { Usaha }\end{array}$ & 40.541 .900 & 8. & $\begin{array}{l}\text { Simpanan } \\
\text { Pokok }\end{array}$ & 6.700 .000 \\
\hline & Jumlah & 97.256 .231 & 9. & $\begin{array}{l}\text { Simpanan } \\
\text { Wajib }\end{array}$ & 70.770 .000 \\
\hline \multicolumn{3}{|c|}{ II. Aktiva Tetap } & & Jumlah & 79.790 .138 \\
\hline 4. & Inv.Kantor & 26.700 .000 & IV & Ekuitas & \\
\hline \multirow[t]{3}{*}{5.} & $\begin{array}{l}\text { Akumulasi } \\
\text { Peny. }\end{array}$ & $(3.102 .083)$ & 10 & $\begin{array}{l}\text { Laba Usaha } \\
\text { ditahan }\end{array}$ & 20.182 .764 \\
\hline & Jumlah & 23.597 .917 & 11 & $\begin{array}{l}\text { Laba Usaha } \\
\text { Berjalan }\end{array}$ & 20.881 .246 \\
\hline & $\begin{array}{l}\text { TOTAl } \\
\text { AKTIVA }\end{array}$ & 120.854 .148 & & & 120.854 .148 \\
\hline
\end{tabular}

\section{Kesimpulan}

1. Jumlah penerimaan modal kerja koperasi dari tahun 2014 sampai tahun 2015 terjadi peningkatan. Peningkatan tersebut adalah tahun 2015 terjadi peningkatan sebesar $16.20 \%$ atau sebesar Rp.19.209.427
2. Peningkatan volume usaha koperasi juga berpengaruh dengan peningkatan modal kerja koperasi, ini terlihat dengan naiknya volume usaha sebesar $16.89 \%$ atau naik sebesar Rp.20.414.174 dari tahun 2014 ke tahun 2015 sedangkan untuk prediksi tahun 2016 akan 
mengalami kenaikan yang sangat

berarti.

\section{Saran}

1. Untuk meningkatkan modal kerja hendaknya pengurus tidak hanya mengandalkan modal yang datang dari dalam, tetapi mengusahakan dari luar, yaitu berupa pinjaman lembaga keuangan yang ada.

2. Sedangkan untuk meningkatkan volume usaha sebaiknya para pengurus mampu bekerja sama dengan pihak-pihak industri dalam rangka pemenuhan produk-produk yang diperlukan anggotanya. Hal ini menjaga kontinuitas produk pada usaha yang sudah dijalankan.

\section{Daftar Pustaka}

Alwi S, : Alat-alat Analisa Dalam Pembelanjaan, Edisi Revisi, cetakan ketiga, bagian penerbit Fakultas Ekonomi Islam Indonesia, Yogyakarta, 1983

Anonim, Undang-undang No. 25 tahun 1992, Pokok-pokok Perkoperasian, Penerbit Pustaka Tinta Mas, Surabaya

Arikunto, S, Prosedur Penelitian Suatu Pengantar, Penerbit PT. Aksara, Jakarta, 1983.

Chaniago A, Perkoperasian Indonesia, Penerbit Angkasa Bandung, 1997

Dajan A, Pengantar Metode Statistik, Lembaga Penelitian Pendidikan dan Penerangan Ekonomi Sosial.

Hadi S, Metodologo Research untuk penulisan paper, skripsi, thesis, desertasi, penerbit yayasan penelitian Fakultas Psikologi UGM Yogyakart, 1992
Kartadinata A, Pengantar Manajemen Keuangan, Edisi Revisi ke 2, PT. Bina Angkasa Jakarta 1983.

Kartono K, Pengantar Metodologi Research Sosial, Alumni Bandung, 1980.

Koentjaraningrat, Metode Penelitian Masyarakat, Penerbit PT. Gramedia Jakarta, 1979.

Manullang M, Pengantar Ekonomi Perusahaan, cetakan ke tiga Perusahaan Daerah Sumut, Deli Medan, 1969

Mas'ud MC, Akuntansi Manajemen, buku satu, edisi Revisi, Cetakan Pertama, Bagian Penerbit Fakultas Ekonomi UGM, Yogyakarta 1982

Munawir S, Analisa Laporan Keuangan, edisi ke 4 Liberty, Yogyakarta, 1993

Nitisemito AS, Pembelanjaan Perusahaan, cetakan ke 5 edisi Revisi 